\title{
Detecting the Turning Points of Grassland Autumn Phenology on the Qinghai-Tibetan Plateau: Spatial Heterogeneity and Controls
}

\author{
Yanzheng Yang ${ }^{1}\left(\mathbb{D}\right.$, Ning Qi $^{2}$, Jun Zhao ${ }^{3}$, Nan Meng ${ }^{1,4}$, Zijian Lu ${ }^{1,5}$, Xuezhi Wang ${ }^{6}$, Le Kang ${ }^{7}$, Boheng Wang ${ }^{7}$, \\ Ruonan $\mathrm{Li}^{1,4}$, Jinfeng $\mathrm{Ma}^{1}$ (D) and Hua Zheng ${ }^{1,4, *}$
}

1 State Key Laboratory of Urban and Regional Ecology, Research Center for Eco-environmental Sciences, Chinese Academy of Sciences, Beijing 100085, China; yangyzh@rcees.ac.cn (Y.Y.); nanmeng_st@rcees.ac.cn (N.M.); 1000480075@smail.shnu.edu.cn (Z.L.); rnli@rcees.ac.cn (R.L.); jfma@rcees.ac.cn (J.M.)

2 School of Information Science \& Technology, Beijing Forestry University, Beijing 100083, China; ningqi830@bjfu.edu.cn

3 China Aero Geophysical Survey \& Remote Sensing Center for Natural Resources, Beijing 100083, China; zhaojun01@mail.cgs.gov.cn

4 University of Chinese Academy of Sciences, Beijing 100049, China

5 School of Environmental and Geographical Sciences, Shanghai Normal University, Shanghai 200234, China 6 Computer Network Information Center, Chinese Academy of Sciences, Beijing 100083, China; wxz@cnic.cn

Citation: Yang, Y.; Qi, N.; Zhao, J.; Meng, N.; Lu, Z.; Wang, X.; Kang, L.; Wang, B.; Li, R.; Ma, J.; et al. Detecting the Turning Points of Grassland Autumn Phenology on the Qinghai-Tibetan Plateau: Spatial Heterogeneity and Controls. Remote Sens. 2021, 13, 4797. https://doi.org/ $10.3390 /$ rs13234797

Academic Editors: Alfredo Huete, Xuanlong Ma, Jiaxin Jin, Xiaolin Zhu, Yuke Zhou and Qiaoyun Xie

Received: 12 October 2021

Accepted: 23 November 2021

Published: 26 November 2021

Publisher's Note: MDPI stays neutral with regard to jurisdictional claims in published maps and institutional affiliations.

Copyright: (C) 2021 by the authors. Licensee MDPI, Basel, Switzerland. This article is an open access article distributed under the terms and conditions of the Creative Commons Attribution (CC BY) license (https:/ / creativecommons.org/licenses/by/ $4.0 /)$.
7 East China Inventory and Planning Institute of the State Administration of Forestry and Grassland, Hangzhou 310019, China; hdybhc@163.com (L.K.); vancywang@126.com (B.W.)

* Correspondence: zhenghua@rcees.ac.cn; Tel.: +86-010-62849134

Abstract: Autumn phenology, commonly represented by the end of season (EOS), is considered to be the most sensitive and crucial productivity indicator of alpine and cold grassland in the Qinghai-Tibetan Plateau. Previous studies typically assumed that the rates of EOS changes remain unchanged over long time periods. However, pixel-scale analysis indicates the existence of turning points and differing EOS change rates before and after these points. The spatial heterogeneity and controls of these turning points remain unclear. In this study, the EOS turning point changes are extracted and their controls are explored by integrating long time-series remote sensing images and piecewise regression methods. The results indicate that the EOS changed over time with a delay rate of 0.08 days/year during 1982-2015. The rates of change are not consistent over different time periods, which clearly highlights the existence of turning points. The results show that temperature contributed most strongly to the EOS changes, followed by precipitation and insolation. Furthermore, the turning points of climate, human activities (e.g., grazing, economic development), and their intersections are found to jointly control the EOS turning points. This study is the first quantitative investigation into the spatial heterogeneity and controls of the EOS turning points on the QinghaiTibetan Plateau, and provides important insight into the growth mechanism of alpine and cold grassland.

Keywords: autumn phenology; turning point; climate changes; human activities; Qinghai-Tibetan Plateau

\section{Introduction}

Vegetation phenology refers to periodically recurring growth patterns [1], and sheds a unique light on how ecosystems respond to climate change [2-4]. Shifts in phenology trends can affect the carbon budget, water flux, and energy balance from a regional to global scale [5]. Regional warming in alpine regions has led to several significant phenology changes, including advancement of the start of the growing season (SOS) in spring and a delay of the end of season (EOS) in autumn, as well as extensions of the growing season [6]. Phenology changes in turn provide strong feedback to climate systems, which can affect the regional carbon and water cycles [7]. The advancement of SOS and its 
controls have been detected in numerous satellite data and observations [8,9]. However, emerging evidence has shown that autumn phenology may contribute more strongly to the growth season length extension than spring phenology, leading to an increase of biomass accumulation [10,11]. Autumn phenology plays a critical role in carbon and nitrogen cycling [12]; it is thus important to track the spatial dynamics of autumn phenology to obtain more accurate information regarding growth season length variations and improve the modeling of biochemical cycles at vegetation-climate intersections [13,14].

With its distinctive geographical and hydrothermal condition, the Qinghai-Tibetan Plateau is regarded as one of the planet's most vulnerable alpine and cold ecosystems because of its strong sensitivity to climate change and has thus become a hotspot of international research [15]. Some degree of consensus has been achieved in recent decades regarding EOS changes on the Qinghai-Tibetan Plateau. Previous studies have shown an overall lengthening of the growing season and extension of the EOS on the Qinghai-Tibetan Plateau due to the warming and increasingly humid climate $[16,17]$. Studies based on a limited number of phenological observations reported that the EOS exhibited advancement trends on a regional scale [18]. Moreover, EOS changes have significantly affected the gross primary productivity (GPP) and evapotranspiration (ET) of alpine and cold ecosystems [15]. Some evidence has demonstrated that EOS is not only controlled by climate conditions and human activities $[19,20]$ but also depends on the previous growth stage (i.e., SOS, annual peak growth time) [21,22], which make the EOS variation controls complex and difficult to constrain. Additional studies are therefore required to more clearly reveal the mechanism of EOS changes.

The major challenge of EOS studies arises from the poorly understood control mechanism. Previous studies have recognized that warmer temperatures and inadequate autumn solar radiation enhance vegetation growth $[22,23]$. Daytime and nighttime temperatures have different impacts on the alpine grassland EOS. However, the effects of higher preseason precipitation or longer sunshine duration on the EOS changes remain unclear [6]. The intersection of a wide variety of climate variables complicates this interpretation. Furthermore, some evidence has shown that human activities (especially grassland grazing) can alter vegetation phenology [24,25], but the superimposed effects of ecological protection and grazing make this effect difficult to quantify.

Recent advances in time-series analysis have demonstrated that ecosystem status changes are gradual but ultimately lead to qualitative changes [26]. The concept of turning points has opened a new research direction of ecosystem status change. Land cover changes, extreme climate, and human disturbances often occur abruptly and can result in ecosystem status changes $[27,28]$, whereas increasing human pressure or grazing may more gradually change the ecosystem. Some previous studies demonstrated that the trend rates of EOS changes tend to vary over long periods, whereas turning points (sometimes referred to as breaking points) are more distinct, with different change rates occurring before and after these points [29]. A turning point of the Qinghai-Tibetan Plateau has traditionally been defined in the year 2000 or the entire study period is taken as a whole [20], but notable variations can be detected at the pixel-scale, which have not been previously reported.

This paper investigates the Qinghai-Tibetan Plateau as a study area to (1) detect the existence of EOS turning points in different subregions, (2) quantify the determined climatic factors before and after the turning points, and (3) explore the contribution of climate change and human activities (grazing, economic development) to the EOS turning points. The detection of EOS turning points at the pixel and regional scale not only enriches the understanding of the EOS controls on alpine and cold grassland but also provides further details to reveal the EOS change mechanisms over different periods and their controls on the Qinghai-Tibetan Plateau. 


\section{Materials and Methods}

\subsection{Study Area}

The Qinghai-Tibetan Plateau is situated in southwestern China and covers all of Tibet and the Qinghai provinces and is also a part of the Xinjiang, Sichuan, Gansu, and Yunnan provinces (Figure 1). The Qinghai-Tibetan Plateau is considered the third pole in the world, has an average altitude of $>4000 \mathrm{~m}$, and is characterized by a plateau monsoon climate with low temperatures, low precipitation, and strong insolation. More than 54\% of the Qinghai-Tibetan Plateau area has a total annual precipitation below $400 \mathrm{~mm}$ and temperatures below $0{ }^{\circ} \mathrm{C}$ [22]. This region is known as the Asia water tower and is home to the headstreams of the Yangtze, Yellow, Lantsang, and Indus rivers. The alpine, cold, and dry climatic conditions lead to unique vegetation types on the Qinghai-Tibetan Plateau. A climate gradient exists from warm-humid in the southeast to cold-dry in the northwest, along which the vegetation types transition from forestland, meadow, steppe, and desert. The grassland, which includes meadow, steppe, and desert steppe, and covers 51.05\% of the Qinghai-Tibetan Plateau area, is the most important ecosystem and sensitive to climate change. An understanding of grassland dynamics under the climate and human disturbance conditions is crucial for regional ecological security.

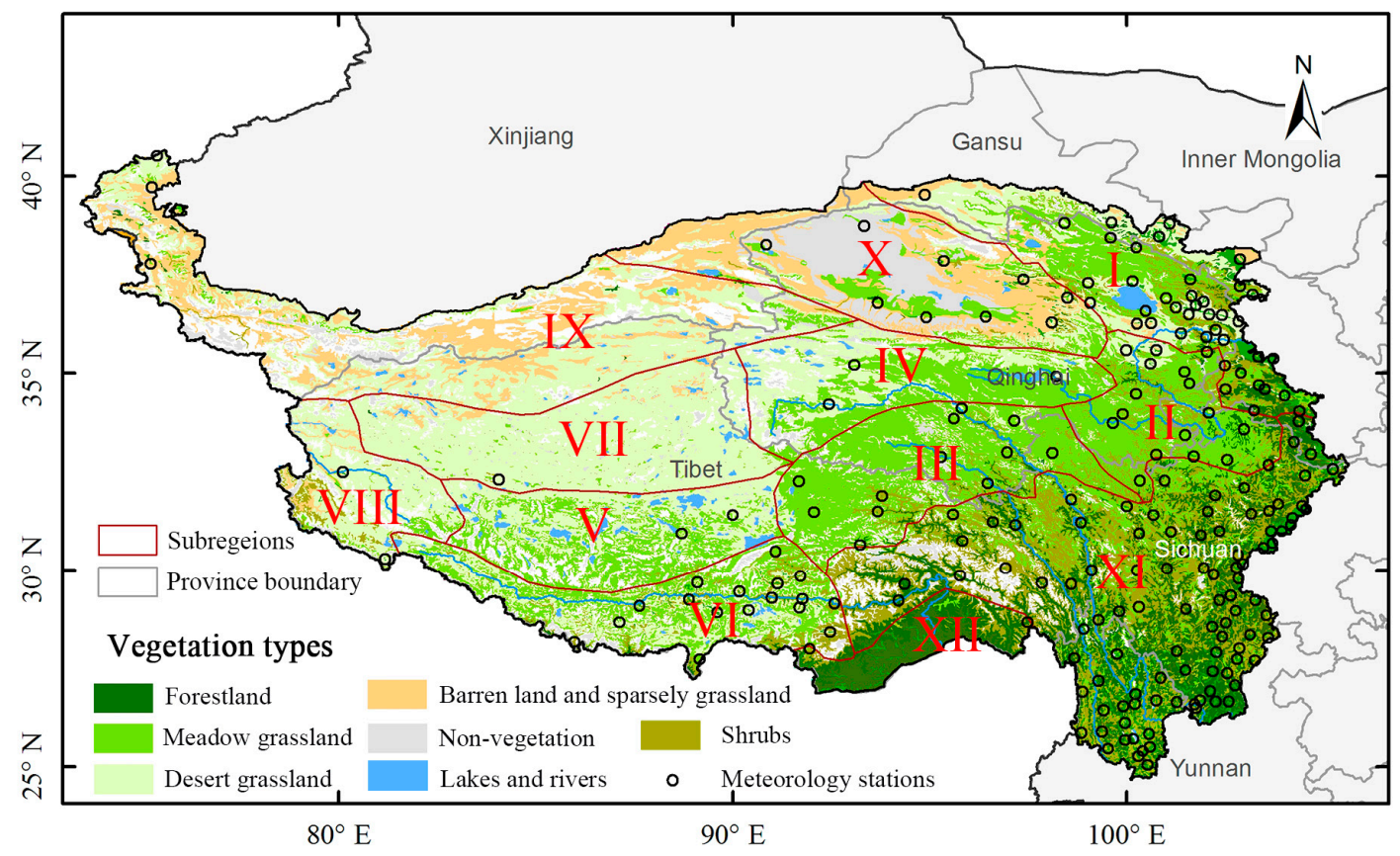

Figure 1. Study area and geographical subregions. The black circles represent the locations of 209 meteorological stations on the Qinghai-Tibetan Plateau.

We divided the entire Qinghai-Tibetan Plateau into 12 subregions (Figure 1, Table 1) based on the bio-geographical division proposed by Zheng et al. [30]. The grassland distribution was extracted according to a China vegetation map (scale $=1: 100,000$ ) [31], eliminating subregions X, XI, and XII, for which the main vegetation types are desert, forestland, and forestland, respectively. Only the remaining nine subregions (I-IX) are analyzed in this study, covering meadow, steppe, and desert grassland (Table 1). Of these nine subregions, we focused in detail on subregion I, which has the highest annual accumulated temperature above $0{ }^{\circ} \mathrm{C}\left(\mathrm{AGDD}_{0}\right)$ and medium moisture index (MI). Subregions II and III had relatively high $\mathrm{MI}$ values that decreased from southeast to northwest. Each subregion exhibited unique climatic conditions and economic development levels, as well as different vegetation responses to climate and human activities. 
Table 1. Description of the Qinghai-Tibetan Plateau subregions. $\mathrm{AGDD}_{0}$ : Annual accumulated temperature above $0{ }^{\circ} \mathrm{C}$. MI: Moisture index calculated by the ratio of the mean annual precipitation to the annual equilibrium evapotranspiration.

\begin{tabular}{|c|c|c|c|c|}
\hline ID & Subregion Names & $\mathrm{AGDD}_{0}$ Means $\left({ }^{\circ} \mathrm{C}\right)$ & MI Means & Main Provinces \\
\hline I & Alpine temperate steppe of the Qinghai Lake Basin & 1311.45 & 0.62 & Qinghai, Gansu \\
\hline II & Alpine meadow steppe on the Zoige Plateau & 981.29 & 1.01 & Qinghai, Sichuan \\
\hline III & Alpine meadow steppe on the Yushu-Naqu Plateau & 670.04 & 0.91 & Qinghai, Tibet \\
\hline IV & Alpine meadow steppe on the sources of the Yangtze and Yellow rivers & 496.14 & 0.57 & Qinghai \\
\hline $\mathrm{V}$ & Alpine and cold grassland on the Southern Chang Tang Plateau & 824.56 & 0.45 & Tibet \\
\hline VI & Alpine temperate grassland of the Brahmaputra River Basin & 917.33 & 0.59 & Tibet \\
\hline VII & Alpine and cold grassland on the Northern Chang Tang Plateau & 618.61 & 0.38 & Tibet \\
\hline VIII & Alpine and cold grassland on the Upper Indus River Basin & 827.01 & 0.24 & Tibet \\
\hline IX & Alpine and cold desert grassland of the Kunlun Mountains & 571.07 & 0.35 & Tibet, Xinjiang \\
\hline$x$ & Alpine desert in the Qaidam Basin & 1699.63 & 0.18 & Qinghai \\
\hline $\mathrm{XI}$ & Alpine forestland in the Hengduan Mountain & 2043.25 & 1.14 & Sichuan, Yunnan \\
\hline XII & Subtropical forestland in the southern Tibet & 3941.97 & 1.86 & Tibet \\
\hline
\end{tabular}

\subsection{Data Source}

The GIMMS NDVI3g dataset provided by NASA was used to estimate the EOS on the Qinghai-Tibetan Plateau. The dataset was available from 1982 to 2015 with an 8-km spatial resolution and 15-day temporal resolution [32]. Some previous processes (e.g., calibration, noise removal) were performed for this version to better detect the vegetation dynamics [32]. This dataset has been widely used to detect long-term vegetation dynamics [33-35]. Due to the normalized difference vegetation index (NDVI) data might be misrepresented by snow [36]; we used the average temperature of a sequence of five days less than $0{ }^{\circ} \mathrm{C}$ to screen out the pixels that might be covered by snow. Temperature, precipitation, and insolation data from 1982-2015 were extracted from the China meteorological forcing dataset (1979-2015) downloaded from the Big Earth Data Platform for Three Poles with a spatial resolution of $0.1^{\circ}$ and temporal resolution of $3 \mathrm{~h}$ (http:/ / poles.tpdc.ac.cn/, Accessed on 15 August 2021) [37].

Human activities, including grazing density and economic development, were quantified using economic statistic data. For example, the grazing density were represented by the number of large animals (one large animal equal to five sheep unit) and sheep, and uniformly converted into sheep units. The economic development levels were quantified as the production of primary, secondary, and tertiary sectors. These data come from the statistical yearbooks of Qinghai and Tibet from 1982 to 2015.

\subsection{Retrieval of EOS}

Numerous methods have been used to fit the NDVI changes from seasonal vegetation cycles. After comparing the fitting results of HANTS [38], Polyfit [39], and Double logistic [40] in the nine subregions, we found that the RMES of HANTS $\left(1.26 \pm 0.24 \times 10^{-5}\right)$ and Polyfit $\left(1.28 \pm 0.24 \times 10^{-5}\right)$ were similar and smaller than the Double logistic results $\left(1.93 \pm 0.43 \times 10^{-5}\right)$ (Figure A1). HANTS and Polyfit, were therefore selected as the two most simple and effective methods to fit the NDVI change curves. Dynamic thresholds were adopted to determine the EOS. Further details of these two fitting methods are described below.

The HANTS method involves the harmonic analysis of a time series, is adapted from the fast Fourier transform, and eliminates cloud noise using the least square method $[38,40]$. The HANTS methods can quickly smooth the data, remove outliers, and fill gaps of missing data. The following Equation (1) was used to fit the NDVI seasonal fluctuation curve:

$$
\operatorname{NDVI}(t)=a_{0}+\sum_{i=1}^{n} a_{i} \cos \left(2 \pi t-\varphi_{i}\right)
$$

where $t$ is the Julian date, $a_{0}$ is the average of all NDVI observations, and $\varphi_{i}$ and $a_{i}$ are the phase and amplitude of the curve, respectively. 
The Polyfit method adopts a polynomial function to fit the NDVI records [39]. The following sixth order Equation (2) is used to describe the NDVI curve:

$$
N D V I(t)=a_{0}+a_{1} t+a_{2} t^{2}+\ldots+a_{6} t^{6}
$$

where $a_{0}-a_{6}$ are regression coefficients determined using the Levenberg-Marquardt method.

The EOS was determined by the day when the smoothed curve of the 34-year mean passed a designated threshold. We first fitted the NDVI changes with HANTS and Polyfit methods and then calculated the $\mathrm{NDVI}_{\text {ratio }}$ (described in Equation (3)) for 365 days with multi-year mean $N D V I$ values, next detected the time $t$ with the minimum $N D V I_{\text {ratio }}$ and used the corresponding $\operatorname{NDVI}(t+1)$ at time $(t+1)$ as the NDVI threshold for the EOS. Finally, we obtained the EOS for 34 years using the threshold:

$$
N D V I_{\text {ratio }}(t)=\frac{N D V I(t+1)-N D V I(t)}{N D V I(t)}
$$

\subsection{Quantification of the EOS Trends, Turning Points, and Controls}

After extracting the EOS at the pixel scale, we first quantified the tendency of the EOS changes using greenness changes methods, and then detected the turning points using the piecewise regression method. The mean EOS values and EOS trends within the subregions were calculated as the EOS and EOS trends at the subregion level. The turning points at a subregion and province level were calculated by the majority values.

The EOS trends were calculated using the greenness rate of change [41]. The EOS was considered delayed if the slope was a positive value; otherwise, the EOS advanced.

$$
\text { slope }=\frac{n \times \sum_{i=1}^{n}(i \times N D V I)-\sum_{i=1}^{n} i \sum_{i=1}^{n} N D V I_{i}}{n \times \sum_{i=1}^{n} i^{2}-\left(\sum_{i=1}^{n} i\right)^{2}}
$$

where $i$ is the order of the year, $n$ is the number of years, $N D V I_{i}$ is the NDVI in the $i^{\text {th }}$ year, and the slope is the vegetation change rate. Alternatively, we can use the unary linear regression, in which the $P$ values and confidence levels can be calculated.

Turning points were identified by piecewise regression [42] analysis, as defined in Equation (5), which can be used to detect sudden and sharp changes in directionality. This method has been widely applied for analyzing vegetation dynamics $[19,43,44]$.

$$
y=\left\{\begin{array}{c}
\beta_{0}+\beta_{1} t+\varepsilon t \leq \alpha \\
\beta_{0}+\beta_{1} t+\beta_{2}(t-\alpha)+\varepsilon t>\alpha
\end{array}\right.
$$

where $t$ is the order of the year, $\alpha$ is the estimated turning point of the vegetation change trend determined using the least square error method, $\beta_{1}$ and $\left(\beta_{1}+\beta_{2}\right)$ are the change rates before and after the turning points, respectively, and $\varepsilon$ is the residual error. We performed $t$-tests to check the significance of the piecewise regressions.

Redundancy analysis (RDA) is a powerful analysis technique that could be applied in separating the contributions of climate, human activities, and their intersections to the EOS changes. RDA is a method to extract and summarize the variation in a set of response variables that can be explained by a set of explanatory variables [45]. In this study, RDA was performed with the vegan package in $\mathrm{R}$ language [46]. In RDA, climatic variables or human activity variables were chosen as predictors to maximize the extent of their correlation with the EOS changes as the response variable. RDA had been widely used in ecology-related studies [47,48]. The turning points of human activities were also calculated with Equation (5). The relationships between the turning points of the EOS and climatic variables were quantified using partial regression analysis or the correlation coefficient. 


\section{Results}

\subsection{EOS Spatial Distribution and Variation Characteristics}

The obtained EOS presented high spatial heterogeneity across the grassland of the Qinghai-Tibetan Plateau during 1982-2015 (Figure 2). The EOS results extracted using the HANTS and Polyfit methods were not consistent, but their spatial distribution trends were similar (Figure 2a,b). The mean multi-year EOS began on the 291th day of the year (end of September) and spanned nearly one month from the southeast to the northwest (Figures 2 and 3a). The EOS started early (around the 277th day) in subregion IX, which has the highest elevation and lowest $\mathrm{AGDD}_{0}$ values, and started late (around the 300th day) in subregions II and III, which are characterized by relatively warm-humid conditions. In the central Qinghai-Tibetan Plateau (subregion V), the EOS occurred on the 295th day. In subregion I, the EOS was early in the west and late in the east with a mean EOS on the 292th day. The spatial heterogeneity variations were significantly controlled by the MI $\left(\mathrm{EOS}=16.55 \times \mathrm{MI}+287.28, \mathrm{R}^{2}\right.$ adj $\left.=0.20^{* *}\right)$, with an early EOS in the drought subregions (IV, VII, VIII, and IX) and late EOS in the relatively humid subregions (II, III, and VI). The EOS spatial heterogeneity was essentially insensitive to $\mathrm{AGDD}_{0}$.

The mean EOS on the Qinghai-Tibetan Plateau exhibited a slow delayed trend with an average rate of 0.08 days/year. The EOS results extracted using the HANTS and Polyfit methods presented similar patterns (Figure 2d,e). Using these two fitting methods, $60.2 \%$ of the study area presented delay trends (27.8\% area is significant), while $39.8 \%$ of the study area presented advance trends ( $13.4 \%$ area is significant). The EOS trends differed between the nine subregions during 1982-2015 (Figure 3b), showing a delay in the northwest and an advance in the southeast. Subregions I and IX showed significantly delayed trends with more than 0.20 days/year. The EOS of subregion II, with a main land use type of wetland, was also delayed by a rate of 0.12 days/year. The EOS in subregion VIII, which is characterized by alpine, cold, and dry climatic conditions, presented a negative trend with the fastest variation rate ( -0.12 days/year) compared with the other subregions. The EOS of subregion IV showed an advanced trend in the north but delayed trend in the south, with a mean EOS trend of 0.02 days/year. The EOS in subregions III and V showed slight advanced trends of -0.02 and -0.01 days/year, respectively. Subregions VI and VII both presented a slightly delayed trend with an average of approximately 0.04 days/year.

\subsection{Detection of EOS Turning Points in the Subregions}

The EOS changed over time and presented delayed trends during 1982-2015, but the rates of change were not fixed in each subregion over different periods, and notable turning points were observed ( $48.2 \%$ is significant) (Figure $4 \mathrm{c})$. For example, in subregion I, the turning point occurs in the year 1994, for which the EOS was delayed before 1994 and slightly advanced after 1994 (Figure 4f). Similarly, subregion II showed a delayed EOS before 2002 and then a slightly advanced EOS after 2002. In the remaining subregions (III, IV, VI, and IX), the change trends were similar and the turning point year was 1994, where the EOS was delayed prior to 1994, suddenly advanced in 1995, and then maintained the previous change trend until 2015. The turning point trends in subregions V, VII, and VIII occurred in 1994, 1994, and 1999 respectively, but were not significant. These results demonstrate that the EOS changes clearly exhibit turning points and a wide range of EOS change trends with significant spatial heterogeneity on the Qinghai-Tibetan Plateau. The pattern of EOS turning points extracted by HANTS and Polyfit (Figure $4 a, b, d, e)$ have a small difference in subregion I and VI. 
Mean
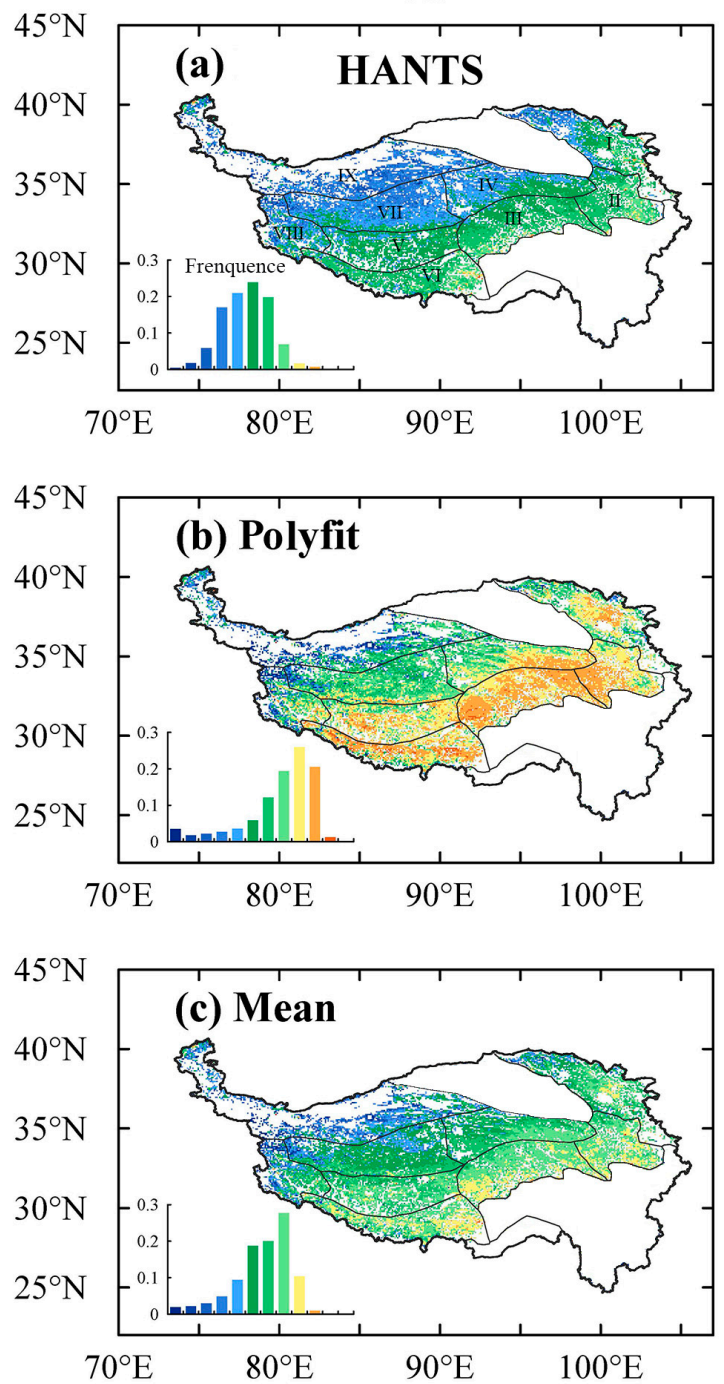

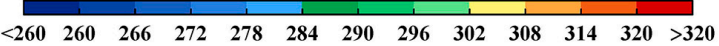

\section{Trend}
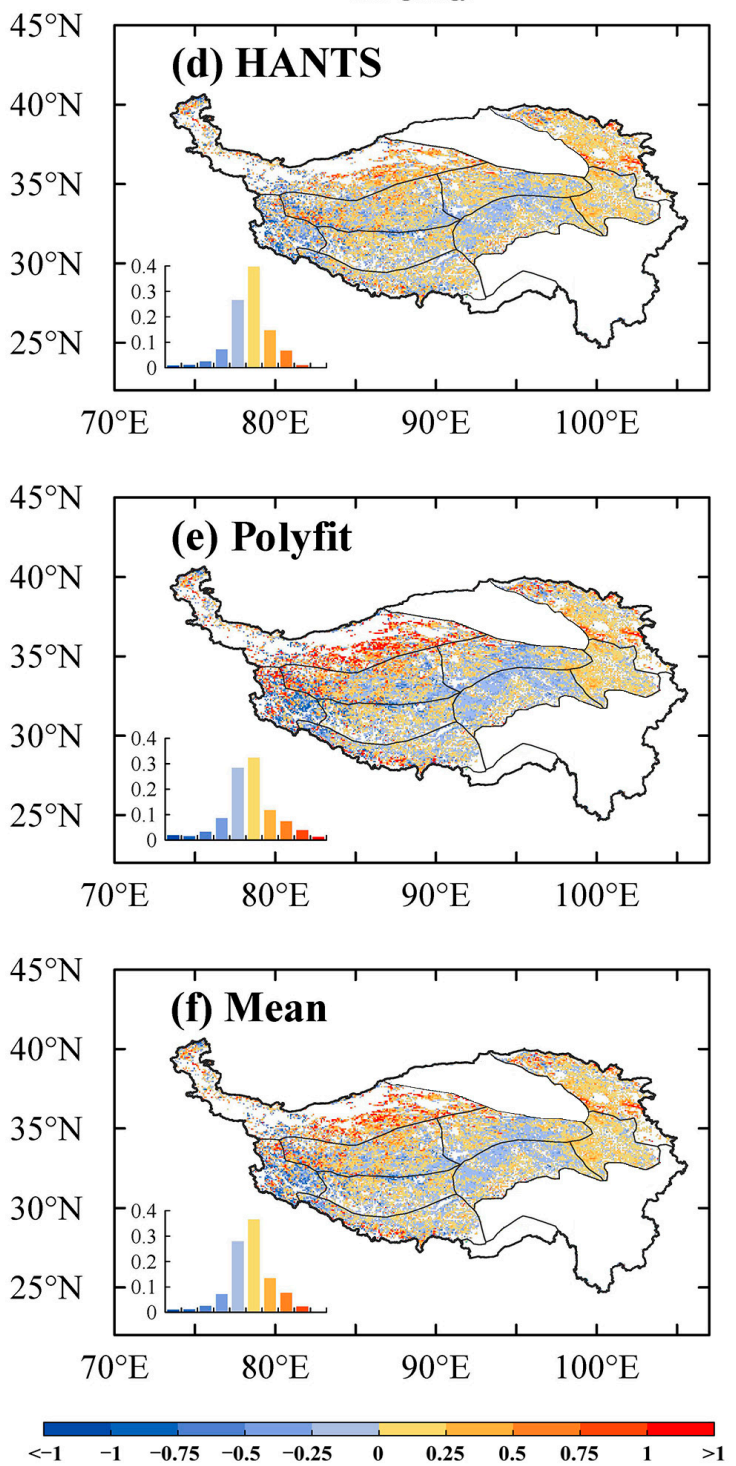

Figure 2. Distributions of the end of season (EOS) (calendar day) and their change trends (days/year). Multi-year means of the EOS obtained using the (a) HANTS method and (b) Polyfit method. (c) Average values of the HANTS and Polyfit methods. Trends of the EOS obtained using the (d) HANTS methods and (e) Polyfit method. (f) Average values of the EOS trends obtained using the HANTS and Polyfit methods.
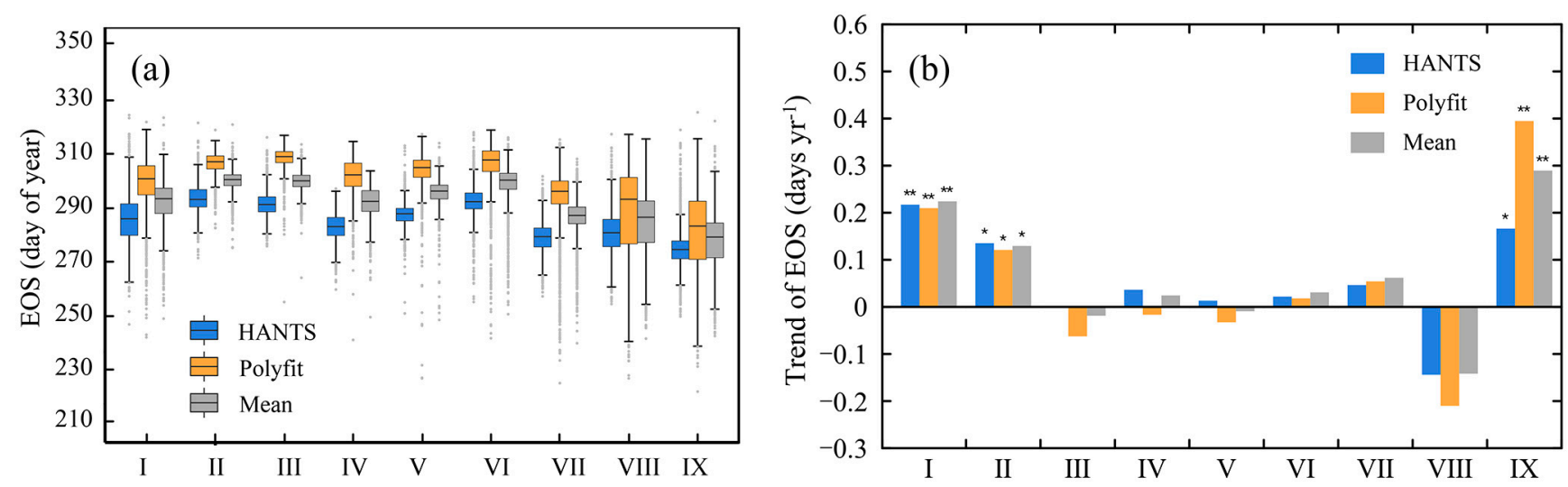

Figure 3. Bar graphs of the (a) mean EOS values and (b) their trends. "*** indicates $p<0.01$ and “*” indicates $p<0.05$. 

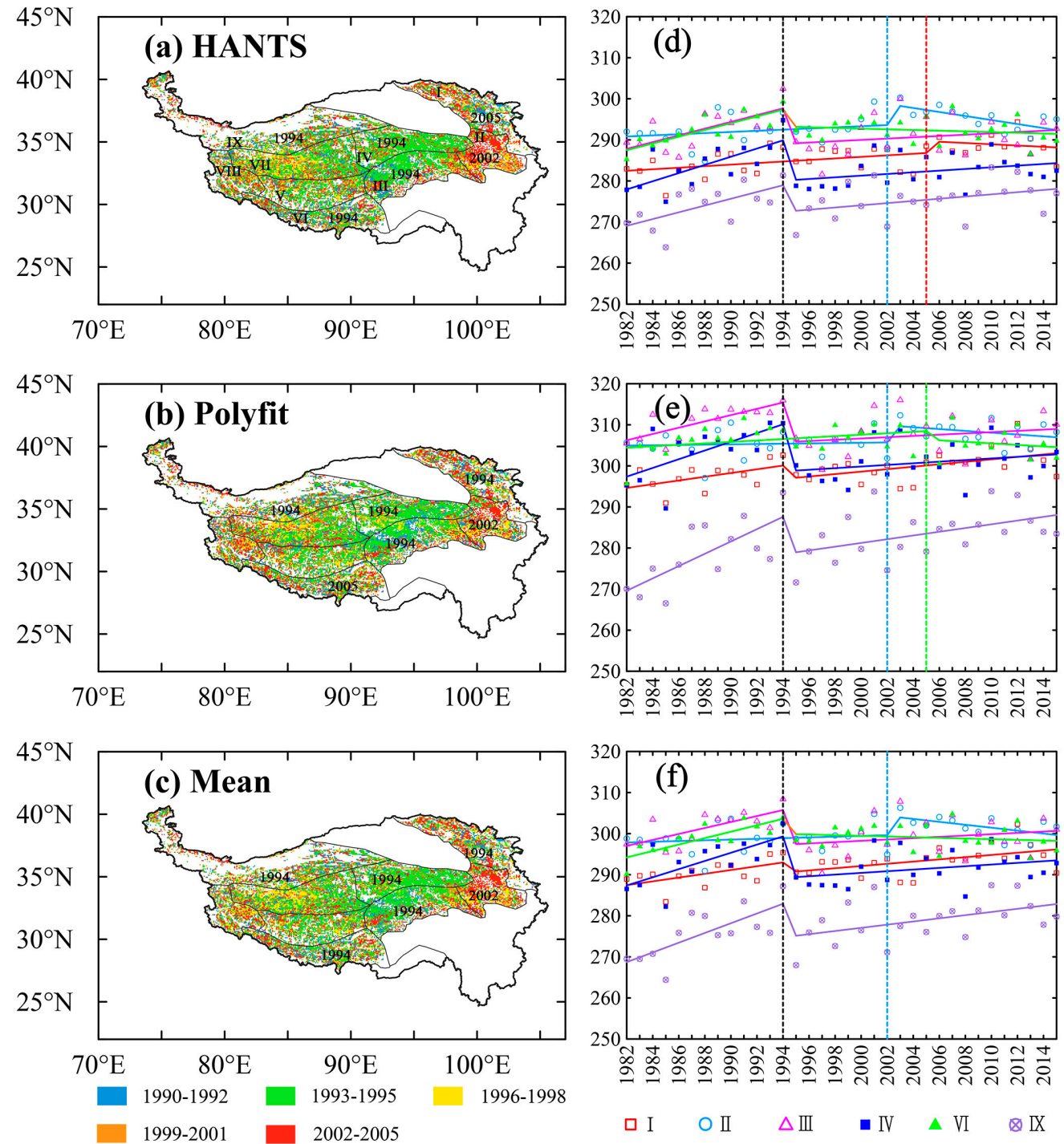

Figure 4. Turning point distributions and variations for subregions. (a-c) EOS turning points distributions with results of HANTS, Polyfit, and their mean values. The numbers represent the modes of the turning years in each subregion. (d-f) Scatter plots and results of piecewise regressions with the results of HANTS, Polyfit, and their mean values. The vertical dashed lines represent the turning points in the different subregions.

\subsection{EOS Variations Controlled by Climatic Variables before and after Turning Points}

The EOS changes exhibited close relationships with the climatic variables, but the dominant climatic variable differed in each subregion before and after its associated turning point (Figure 5). Temperature was the dominant control over the EOS changes in most subregions (I, II, IV, VI, VII, VIII, and IX) before and after the turning point year. In contrast, subregion III showed that the EOS was mainly controlled by the precipitation. Central subregion VII showed that the EOS was jointly controlled by the effects of temperature and precipitation. The area where the EOS changes was controlled by temperature covered the largest proportion, followed by precipitation and insolation (Figure $5 \mathrm{~d}$ ). The results indicate that the proportions controlled by each climate variable changed before and after the turning point years. For example, the EOS in subregion $\mathrm{V}$ was controlled by precipitation before the turning point, which then switched to temperature (Figure A2). The EOS of only approximately $40 \%$ of the area in subregion VI was significantly controlled by temperature prior to the turning point, which thereafter increased to $70 \%$. Contribution of climates to EOS variation are similar with the fitting results of HANTs and Polyfit (Figure A3). 

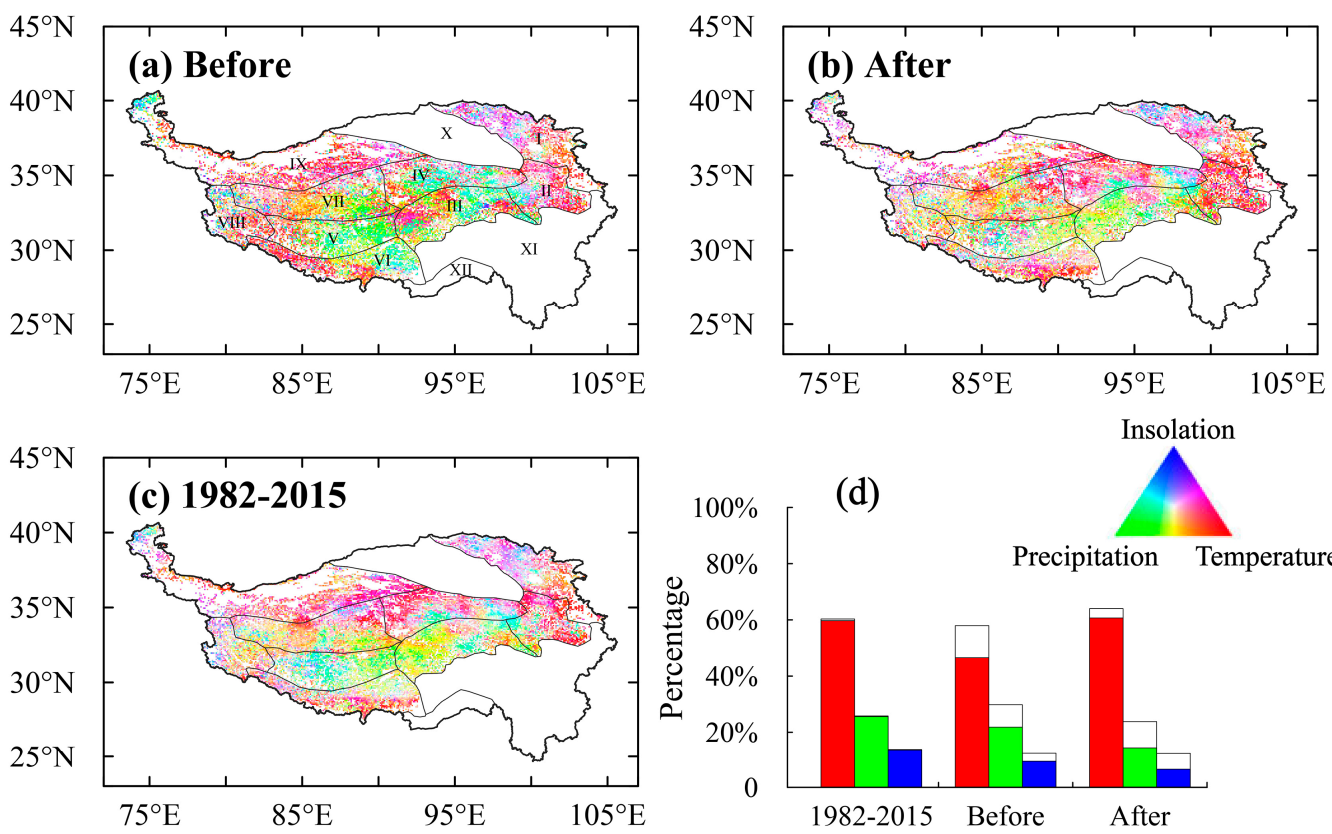

Figure 5. Relative influence of different climate variables (temperature, precipitation, and insolation) on EOS changes before (a) and after (b) the turning point, and over the entire study period (c) with the EOS means values of HANTS and Polyfit methods. (d) Area proportions controlled by the different dominant climate variables.

\subsection{Controls on the EOS Turning Points}

The changes of the annual EOS turning points are consistent with the turning points of the climate variables in most subregions (Table 2). In subregions I and II, the year of the EOS turning point coincides with the year of the insolation and precipitation turning points, respectively. Furthermore, the years of the EOS and temperature turning points are consistent in subregions III-IX. The major determining climatic variable for the EOS turning points is precipitation, followed by temperature and insolation. The relationship with the EOS turning point and insolation is generally weak $\left(R^{2}<0.05\right)$.

Table 2. Correlation coefficients and $\mathrm{P}$ values between the turning points of the EOS and the turning points of climate variables.

\begin{tabular}{ccc}
\hline The EOS Turning Points versus Climate Turning Points & $\mathbf{R}^{\mathbf{2}}$ & $\boldsymbol{p}$ Value \\
\hline EOS temperature & 0.331 & $<0.01$ \\
EOS precipitation & 0.378 & $<0.01$ \\
EOS insolation & 0.038 & 0.76 \\
\hline
\end{tabular}

The relationship between the EOS and human activities was studied at the province level owing to limited statistical data in certain counties and subregions. The economic data show a consistent turning point with the EOS. Before the turning point year ( 1996 for Qinghai and 1995 for Tibet), Qinghai maintained a large amount of sheep, which reflected high grazing activity, and the economic development was slow with low production in the primary, secondary, and tertiary sectors. However, after the turning point year, the grazing intensity decreased and reached a stable change rate, whereas the economy developed rapidly, especially in the secondary sector. For Tibet, the grazing intensity was small before the turning point year but showed a rapid growth rate after the turning point. Similar to Qinghai, Tibet experienced fast economic growth after the turning point, especially in the tertiary sector.

At the province level, the annual EOS was closely related to climate, human activities, and their intersections (Table 3). For Qinghai, a combination of the turning points of climate and human activities can explain $78.86 \%$ of the EOS turning points changes, with climate 
independently accounting for $40.22 \%$ and human activities accounting for $10.45 \%$. The intersections of climate and human activities can explain $28.19 \%$ of the EOS variation in Qinghai. In Tibet, the EOS change due to climate $(66.17 \%)$ was larger than that in Qinghai and the effect of human activities (6.8\%) was weaker. The climate and human activities intersections in Tibet (9.98\%) were also smaller than in Qinghai.

Table 3. Independent contributions of the turning points of climate, human activities, and their intersections to the annual turning points variations of EOS at the province level.

\begin{tabular}{cccc}
\hline Provinces & $\begin{array}{c}\text { Climate } \\
\text { Independent (\%) }\end{array}$ & $\begin{array}{c}\text { Human Activities } \\
\text { Independent (\%) }\end{array}$ & $\begin{array}{c}\text { Climate-Human Activities } \\
\text { Intersections (\%) }\end{array}$ \\
\hline Qinghai & 40.22 & 10.45 & 28.19 \\
Tibet & 66.17 & 6.80 & 9.98 \\
\hline
\end{tabular}

\section{Discussion}

\subsection{Controls on the EOS and EOS Turning Points}

This study is the first to demonstrate pixel-scale spatial heterogeneity of the EOS turning points and explain the turning point controls. The results indicate that the joint effects of climate variables and human activities are the main controls of the EOS turning points. The response of the EOS to environmental changes is complex. Some previous studies indicated that temperature plays a crucial role in EOS regulation [49] however, we show that the temperature control over the EOS is regulated by precipitation and insolation in the meadow and grassland ecotones. The cause of the turning points in most subregions is the abrupt change of temperature and precipitation. The results also reveal that insolation contributed considerably to the EOS changes, which is consistent with some previous reports that the EOS and its relation with GPP is mainly limited by insolation [50]. Other studies have reported that meadow shrinkage, decreased land cover, land albedo changes, and permafrost and seasonal frozen soil dynamics intersect with climate change, which alters the EOS trends [51].

Grazing is the most important human activity that affects grassland dynamics on the Qinghai-Tibetan Plateau [52]. The spatial heterogeneity of community increases, community function alteration, and biodiversity loss are considered to be some of the key disturbances that result in grassland degradation $[53,54]$. The pika population could also increase the effects of animal distribution on vegetation [55]. Overgrazing reduces the vegetation biomass and height, and restricts the regrowth ability of grassland. Our analysis shows that grazing activities in Qinghai notably decreased around 1998, coinciding with the implementation of national conservation policies (e.g., ecological compensation, restoration of degraded grassland). Grazing in Tibet was not active before 1995 and then rapidly increased, however grazing decreased after 2005 due to the late implementation of ecological conservation projects. The primary industry (mostly agriculture and animal husbandry) increased by nearly a factor of five in 1996-2015 compared with that in 1982-1994, which is also consistent with the EOS change turning points. The tertiary industry in Qinghai and Tibet quickly increased after the turning points, which indirectly reflects the intensification of human activities on the Qinghai-Tibetan Plateau.

\subsection{Ecological Significance of the EOS and Its Turning Points}

Phenological changes have great effects on the structure and function of ecosystems. At the community level, various species have different phenological responses to climate change, whereas the EOS can lead to a change in the competition for light and water conditions $[17,56]$. Moreover, plant species changes in the community introduced by the EOS can lead to phenological mismatches; for example, the period of high consumer demand for a resource does not match with the period of resource abundance [57]. At the ecosystem level, phenological grassland changes can modify certain land surface parameters (e.g., albedo, sensible heat flux, evaporation, boundary layer conductivity), 
which affects the regional carbon and water cycles [58]. For example, a later EOS may promote GPP and cause plants to close their stomates and increase water use efficiency if a soil deficit exists [59]. Moreover, the delayed EOS may also increase transpiration and partly offset the GPP, therefore leading to closer relationships between the net ecosystem productivities and EOS changes [60].

The existence of turning points indicates that the EOS trend over long-time periods does not remain unchanged, and the rates of EOS changes differ before and after these points. This observation has several advantages in ecosystem-related studies. First, climatic controls on the EOS in the Qinghai-Tibetan Plateau intersect with each other and follow non-linear relationships with the EOS. An analysis of the EOS before and after the turning points therefore helpful to evaluate the climatic driving mechanisms of the EOS. Second, the detection of spatial heterogeneity of the turning points is helpful for evaluating the large-scale implementation effects of ecological conservation projects. Third, an analysis of the turning points of the EOS relationships with ecosystem functions and services provide important guidelines for fine ecology planning and the development of protection policies.

\subsection{Uncertainties, Challenges, and Future Directions}

The uncertainties in this study arise from three aspects. First, although the EOS trends are consistent with the findings of MODIS NDVI and SPOT NDVI, some design shortcomings in the AVHRR sensor may potentially introduce noise into the GIMMS $3 g$ NDVI dataset. Second, the human activities are difficult to quantify for lack of grazing data (intensity and boundary) and statistic data on the county levels for a long time. Third, there is a limited number of phenological stations on the Qinghai-Tibetan Plateau, and most are distributed in the east, which thus does not represent the EOS changes of the entire plateau. The results of the EOS extraction are not fully calibrated by observations owing to limited data availability.

We recommended the following perspectives for future studies. First, extreme climate events (e.g., cold, frost, drought) may have a more direct effect on vegetation phenology than gradual changes in mean climatic conditions [27,28]. Non-structural carbohydrate storage in plants is helpful to avoid damage caused by extreme events [61]. However, extreme climate conditions with variable frequencies and intensities in different seasons on the Qinghai-Tibetan Plateau require rigorous quantification. Second, although many studies have quantified the effects of climate variables in different seasons, spring phenology, growth season length, and human disturbances on the EOS changes, the joint contribution of these variables is low and the control mechanisms of the EOS and its turning points remain poorly understood. The strengthening and development of phenological observations stations are therefore necessary to explain the mechanism of phenology changes in the Qinghai-Tibetan Plateau. Third, ecosystem models are essential tools for simulating the carbon cycle in both historic and future climate scenarios however, their accuracies remain limited by the understanding of the EOS [62]. More reasonable algorithms and reliable observations are required to calibrate the ecosystem models, which will ultimately provide a new research direction but presently faces serious challenges.

\section{Conclusions}

This study applied multiple statistical methods and long-time series remote sensing data to determine the spatial heterogeneity and controls of autumn phenology on the Qinghai-Tibetan Plateau. The results are summarized as follows. (1) EOS turning points exhibit notable spatial heterogeneities. (2) The climatic controls of the EOS before and after the turning points varied in different subregions on the Qinghai-Tibetan Plateau. (3) Changes in the turning points are controlled by the joint effects of climate and human activities (grazing and economic development). This study is the first to demonstrate the spatial heterogeneity of turning points at a pixel scale and discuss their controls on the Qinghai-Tibetan Plateau, which is useful for exploring the mechanism of EOS changes and developing regional ecosystem conservation measures. 
Author Contributions: Conceptualization, Y.Y. and N.Q.; methodology, N.Q.; validation, N.Q., J.Z., X.W. and L.K.; writing — original draft preparation, Y.Y. and N.Q.; writing-review and editing, N.M., Z.L., B.W., J.M. and R.L.; project administration, H.Z.; funding acquisition, H.Z. All authors have read and agreed to the published version of the manuscript.

Funding: This research was funded by The Second Tibetan Plateau Scientific Expedition and Research Program (STEP) (Grant No. 2019QZKK0307), the National Natural Science Foundation of China (41925005, 41701051, and 41801181) and Special Program of Research Center for Eco-environmental Sciences, CAS (RCEES-TDZ-2021-11).

Informed Consent Statement: Not applicable.

Data Availability Statement: The GIMMS 3g NDVI data presented in this study are openly available at the National Qinghai-Tibetan Plateau Data Center at [http:/ / poles.tpdc.ac.cn/en/data/9775f2b4 -7370-4e5e-a537-3482c9a83d88/. Accessed on 1 May 2021]. The climate data were downloaded from A Big Earth Data Platform for Three Poles with a spatial resolution of $0.1^{\circ}$ and temporal resolution of 3 h [http:/ / poles.tpdc.ac.cn/zh-hans/data/7a35329c-c53f-4267-aa07-e0037d913a21/. Accessed on 1 May 2021].

Conflicts of Interest: The authors declare no conflict of interest.

\section{Appendix A}

(a)

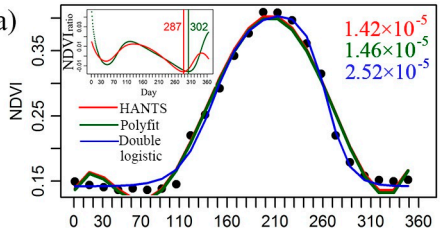

(d)
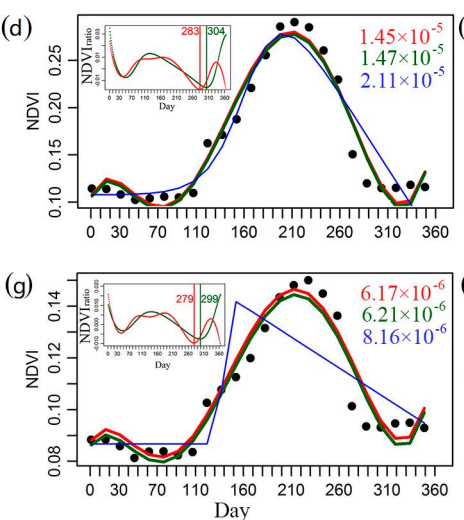
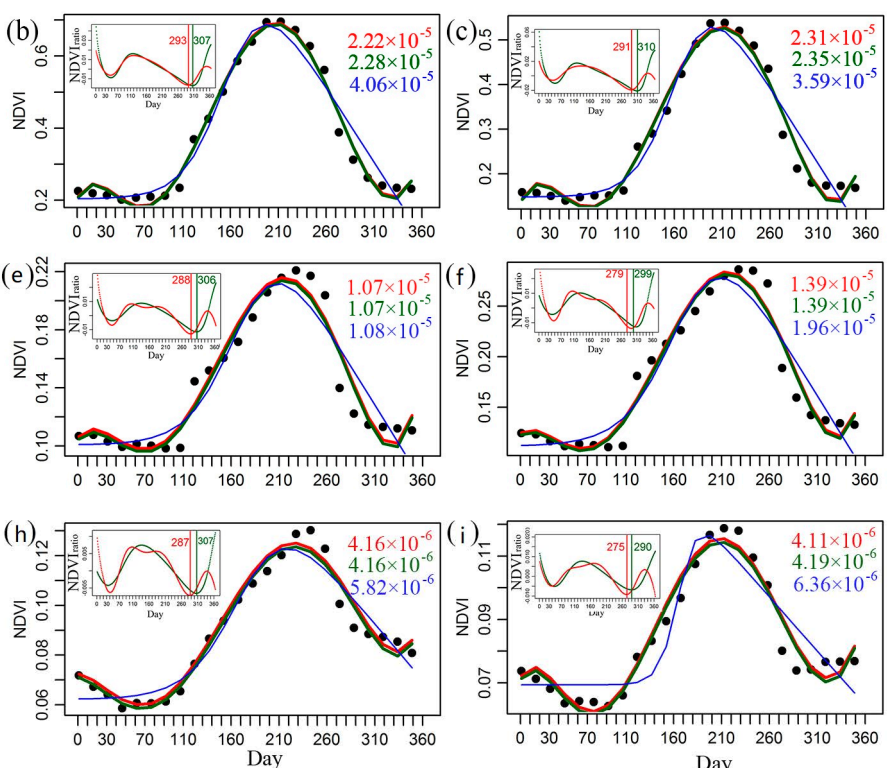

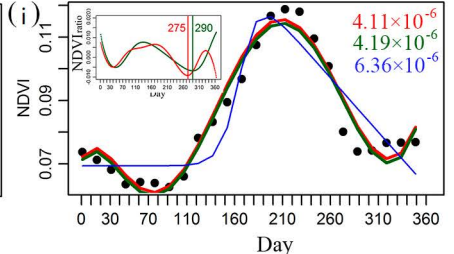

Figure A1. The NDVI fitting results of three equations, including HANTS (red lines and numbers), Polyfit (green lines and numbers), and Double logistic (red lines and numbers). (a-i) represent subregions I-IX, respectively. The upper-left panels are corresponding $\mathrm{NDVI}_{\text {ratio }}$ changes and EOS with HANTS and Polyfit fitting methods. The upper-right numbers are RMESs for three fitting methods. 

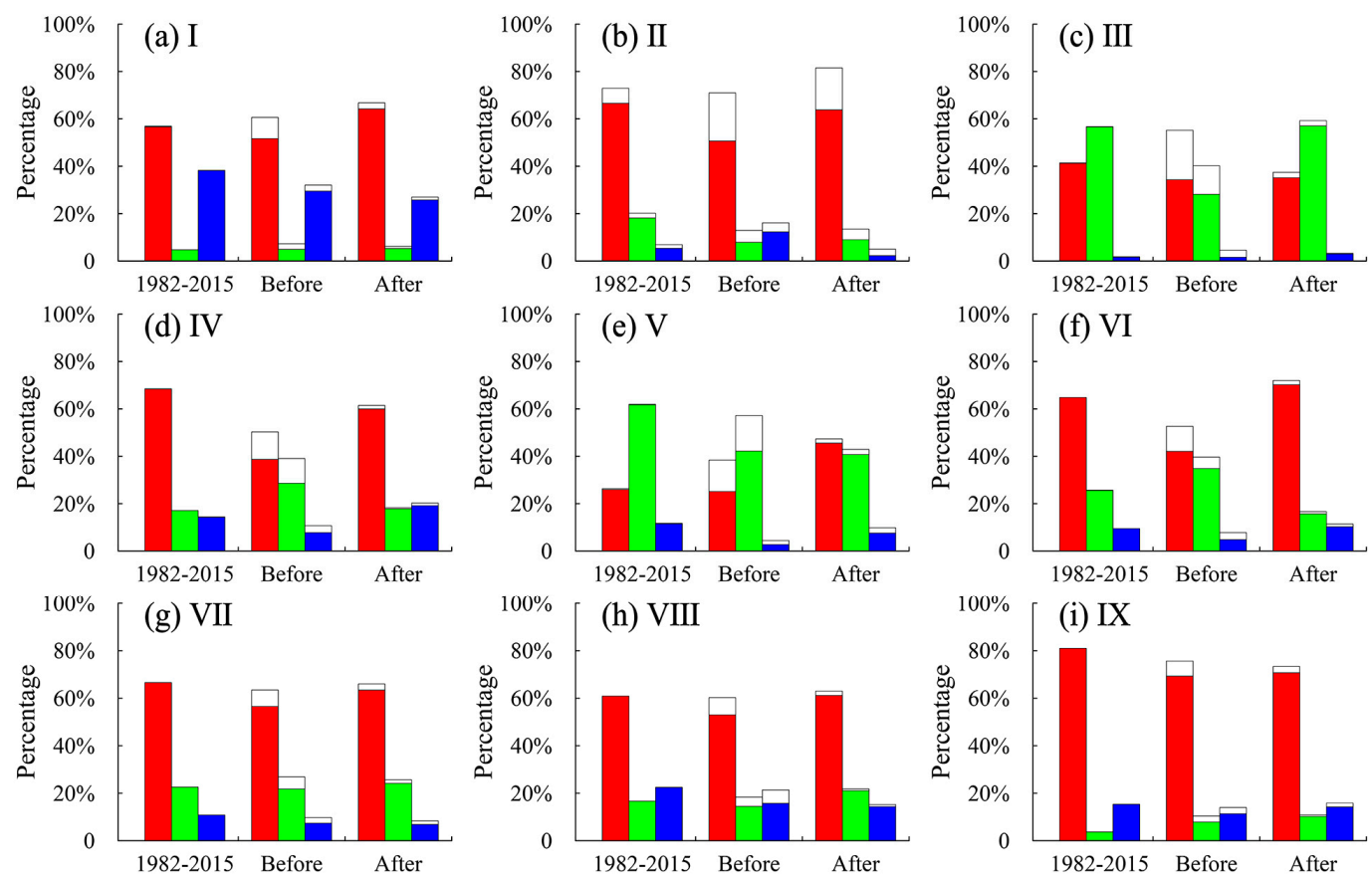

Figure A2. Relative proportions of the three climate variables that contributed to the EOS in each subregion. The legend coloring is same as in Figure 5. The white portions indicate that the proportion is not significant $(p>0.05)$.
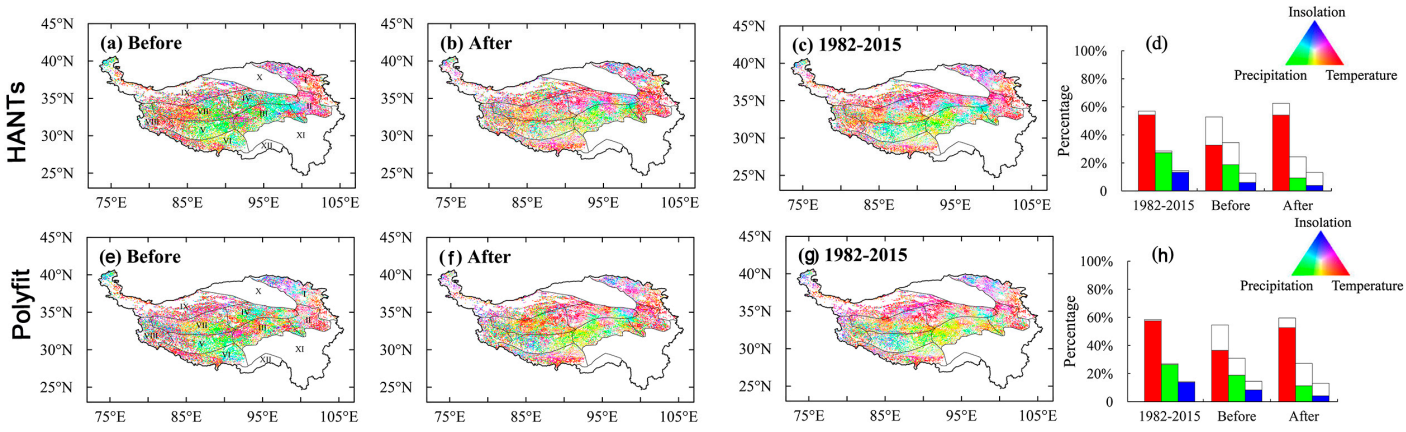

Figure A3. Relative influence of different climate variables (temperature, precipitation, and insolation) on EOS changes before $(\mathbf{a}, \mathbf{e})$ and after $(\mathbf{b}, \mathbf{f})$ the turning point, and over the entire study period $(\mathbf{c}, \mathbf{g})$ with the EOS values of HANTS and Polyfit methods respectively. $(\mathbf{d}, \mathbf{h})$ Area proportions controlled by the different dominant climate variables with results of HANTS and Polyfit methods.

\section{References}

1. Lieth, H. Phenology and Seasonality Modeling; Springer Science \& Business Media: New York, NY, USA, $1974 ;$ Volume 8.

2. Wang, J.; Sun, H.; Xiong, J.; He, D.; Cheng, W.; Ye, C.; Yong, Z.; Huang, X. Dynamics and drivers of vegetation phenology in three-river headwaters region based on the Google Earth engine. Remote Sens. 2021, 13, 2528. [CrossRef]

3. Qiao, C.; Shen, S.; Cheng, C.; Wu, J.; Jia, D.; Song, C. Vegetation Phenology in the Qilian Mountains and its response to temperature from 1982 to 2014. Remote Sens. 2021, 13, 286. [CrossRef]

4. Bornez, K.; Richardson, A.D.; Verger, A.; Descals, A.; Penuelas, J. Evaluation of vegetation and PROBA-V phenology using PhenoCam and Eddy covariance data. Remote Sens. 2020, 12, 3077. [CrossRef]

5. Wang, S.Y.; Zhang, B.; Yang, Q.C.; Chen, G.S.; Yang, B.J.; Lu, L.L.; Shen, M.; Peng, Y.Y. Responses of net primary productivity to phenological dynamics in the Tibetan Plateau, China. Agric. For. Meteorol. 2017, 232, 235-246. [CrossRef]

6. An, S.; Chen, X.Q.; Zhang, X.Y.; Lang, W.G.; Ren, S.L.; Xu, L. Precipitation and minimum temperature are primary climatic controls of alpine grassland autumn phenology on the Qinghai-Tibet plateau. Remote Sens. 2020, 12, 431. [CrossRef]

7. Gonsamo, A.; Chen, J.M.; Ooi, Y.W. Peak season plant activity shift towards spring is reflected by increasing carbon uptake by extratropical ecosystems. Glob. Chang. Biol. 2018, 24, 2117-2128. [CrossRef]

8. Li, X.T.; Guo, W.; Li, S.H.; Zhang, J.Z.; Ni, X.N. The different impacts of the daytime and nighttime land surface temperatures on the alpine grassland phenology. Ecosphere 2021, 12, e03578. [CrossRef] 
9. Lehikoinen, A.; Lindén, A.; Karlsson, M.; Andersson, A.; Crewe, T.L.; Dunn, E.H.; Gregory, G.; Karlsson, L.; Kristiansen, V.; Mackenzie, S.; et al. Phenology of the avian spring migratory passage in Europe and North America: Asymmetric advancement in time and increase in duration. Ecol. Indic. 2019, 101, 985-991. [CrossRef]

10. Zhu, W.Q.; Tian, H.Q.; Xu, X.F.; Pan, Y.Z.; Chen, G.S.; Lin, W.P. Extension of the growing season due to delayed autumn over mid and high latitudes in North America during 1982-2006. Glob. Ecol. Biogeogr. 2012, 21, 260-271. [CrossRef]

11. Bao, G.; Tuya, A.; Bayarsaikhan, S.; Dorjsuren, A.; Mandakh, U.; Bao, Y.H.; Li, C.L.; Vanchindorj, B. Variations and climate constraints of terrestrial net primary productivity over Mongolia. Quat. Int. 2020, 537, 112-125. [CrossRef]

12. Wu, C.; Gough, C.M.; Chen, J.M.; Gonsamo, A. Evidence of autumn phenology control on annual net ecosystem productivity in two temperate deciduous forests. Ecol. Eng. 2013, 60, 88-95. [CrossRef]

13. Sarvia, F.; De Petris, S.; Borgogno-Mondino, E. Exploring climate change effects on vegetation phenology by MOD13Q1 data: The piemonte region case study in the period 2001-2019. Agronomy 2021, 11, 555. [CrossRef]

14. Richardson, A.D.; Keenan, T.F.; Migliavacca, M.; Ryu, Y.; Sonnentag, O.; Toomey, M. Climate change, phenology, and phenological control of vegetation feedbacks to the climate system. Agric. For. Meteorol. 2013, 169, 156-173. [CrossRef]

15. Cheng, M.; Jin, J.X.; Jiang, H. Strong impacts of autumn phenology on grassland ecosystem water use efficiency on the Tibetan Plateau. Ecol. Indic. 2021, 126, 107682. [CrossRef]

16. Dong, M.; Jiang, Y.; Zheng, C.; Zhang, D. Trends in the thermal growing season throughout the Tibetan Plateau during 1960-2009. Agric. For. Meteorol. 2012, 166-167, 201-206. [CrossRef]

17. Shen, M.G.; Piao, S.L.; Dorji, T.; Liu, Q.; Cong, N.; Chen, X.Q.; An, S.; Wang, S.P.; Wang, T.; Zhang, G.X. Plant phenological responses to climate change on the Tibetan Plateau: Research status and challenges. Natl. Sci. Rev. 2015, 2, 454-467. [CrossRef]

18. Chen, X.Q.; An, S.; Inouye, D.W.; Schwartz, M.D. Temperature and snowfall trigger alpine vegetation green-up on the world's roof. Glob. Chang. Biol. 2015, 21, 3635-3646. [CrossRef]

19. Zhang, G.; Zhang, Y.; Dong, J.; Xiao, X. Green-up dates in the Tibetan Plateau have continuously advanced from 1982 to 2011. Proc. Natl. Acad. Sci. USA 2013, 110, 4309-4314. [CrossRef]

20. Li, P.; Peng, C.; Wang, M.; Luo, Y.; Li, M.; Zhang, K.; Zhang, D.; Zhu, Q. Dynamics of vegetation autumn phenology and its response to multiple environmental factors from 1982 to 2012 on Qinghai-Tibetan Plateau in China. Sci. Total Environ. 2018, 637-638, 855-864. [CrossRef]

21. Fu, Y.S.H.; Campioli, M.; Vitasse, Y.; De Boeck, H.J.; Van den Berge, J.; AbdElgawad, H.; Asard, H.; Piao, S.; Deckmyn, G.; Janssens, I.A. Variation in leaf flushing date influences autumnal senescence and next year's flushing date in two temperate tree species. Proc. Natl. Acad. Sci. USA 2014, 111, 7355-7360. [CrossRef]

22. Peng, J.; Wu, C.Y.; Wang, X.Y.; Lu, L.L. Spring phenology outweighed climate change in determining autumn phenology on the Tibetan Plateau. Int. J. Climatol. 2021, 41, 3725-3742. [CrossRef]

23. Cheng, M.; Jin, J.X.; Zhang, J.M.; Jiang, H.; Wang, R.Z. Effect of climate change on vegetation phenology of different land-cover types on the Tibetan Plateau. Int. J. Remote Sens. 2018, 39, 470-487. [CrossRef]

24. Chen, J.; Yan, F.; Lu, Q. Spatiotemporal Variation of Vegetation on the Qinghai-Tibet Plateau and the Influence of Climatic Factors and Human Activities on Vegetation Trend (2000-2019). Remote Sens. 2020, 12, 3150. [CrossRef]

25. Huang, K.; Zhang, Y.; Zhu, J.; Liu, Y.; Zu, J.; Zhang, J. The Influences of Climate Change and Human Activities on Vegetation Dynamics in the Qinghai-Tibet Plateau. Remote Sens. 2016, 8, 876. [CrossRef]

26. Horion, S.; Prishchepov, A.V.; Verbesselt, J.; de Beurs, K.; Tagesson, T.; Fensholt, R. Revealing turning points in ecosystem functioning over the Northern Eurasian agricultural frontier. Glob. Chang. Biol. 2016, 22, 2801-2817. [CrossRef]

27. Li, P.; Liu, Z.; Zhou, X.; Xie, B.; Li, Z.; Luo, Y.; Zhu, Q.; Peng, C. Combined control of multiple extreme climate stressors on autumn vegetation phenology on the Tibetan Plateau under past and future climate change. Agric. For. Meteorol. 2021, 308-309, 108571. [CrossRef]

28. Siegmund, J.F.; Wiedermann, M.; Donges, J.F.; Donner, R.V. Impact of temperature and precipitation extremes on the flowering dates of four German wildlife shrub species. Biogeosciences 2016, 13, 5541-5555. [CrossRef]

29. Bao, G.; Jin, H.; Tong, S.; Chen, J.; Huang, X.; Bao, Y.; Shao, C.; Mandakh, U.; Chopping, M.; Du, L. Autumn Phenology and Its Covariation with Climate, Spring Phenology and Annual Peak Growth on the Mongolian Plateau. Agric. For. Meteorol. 2021, 298-299, 108312. [CrossRef]

30. Zheng, D. The Systematic Study of Ecogeographical Regions in China; Commercial Press: Beijing, China, 2008.

31. Editorial Committee of Chinese Vegetation Map. Vegetation Map of the People's Republic of China (1:1000000); Geological Publishing House: Beijing, China, 2006.

32. Pinzon, J.E.; Tucker, C.J. A Non-Stationary 1981-2012 AVHRR NDVI3g Time Series. Remote Sens. 2014, 6, 6929-6960. [CrossRef]

33. Deng, G.R.; Zhang, H.Y.; Yang, L.B.; Zhao, J.J.; Guo, X.Y.; Hong, Y.; Wu, R.H.; Dan, G. Estimating Frost during Growing Season and Its Impact on the Velocity of Vegetation Greenup and Withering in Northeast China. Remote Sens. 2020, 12, 1355. [CrossRef]

34. Wu, J.H.; Liang, S.L. Assessing Terrestrial Ecosystem Resilience using Satellite Leaf Area Index. Remote Sens. 2020, 12, 595. [CrossRef]

35. Wang, X.F.; Xiao, J.F.; Li, X.; Cheng, G.D.; Ma, M.G.; Zhu, G.F.; Arain, M.A.; Black, T.A.; Jassal, R.S. No trends in spring and autumn phenology during the global warming hiatus. Nat. Commun. 2019, 10, 10. [CrossRef]

36. Shen, M.G.; Sun, Z.Z.; Wang, S.P.; Zhang, G.X.; Kong, W.D.; Chen, A.P.; Piao, S.L. No evidence of continuously advanced green-up dates in the Tibetan Plateau over the last decade. Proc. Natl. Acad. Sci. USA 2013, 110, E2329. [CrossRef] 
37. He, J.; Yang, K. China meteorological forcing dataset (1979-2015). In A Big Earth Data Platform for Three Poles: 2016; Northwest Institute of Eco-Environment and Resources: Lanzhou, China, 2016.

38. Jakubauskas, M.E.; Legates, D.R.; Kastens, J.H. Harmonic analysis of time-series AVHRR NDVI data. Photogramm. Eng. Remote Sens. 2001, 67, 461-470.

39. Piao, S.L.; Fang, J.Y.; Zhou, L.M.; Ciais, P.; Zhu, B. Variations in satellite-derived phenology in China's temperate vegetation. Glob. Chang. Biol. 2006, 12, 672-685. [CrossRef]

40. Liu, Q.; Fu, Y.S.H.; Zeng, Z.Z.; Huang, M.T.; Li, X.R.; Piao, S.L. Temperature, precipitation, and insolation effects on autumn vegetation phenology in temperate China. Glob. Chang. Biol. 2016, 22, 644-655. [CrossRef]

41. Stow, D.; Daeschner, S.; Hope, A.; Douglas, D.; Petersen, A.; Myneni, R.; Zhou, L.; Oechel, W. Variability of the seasonally integrated normalized difference vegetation index across the north slope of Alaska in the 1990s. Int. J. Remote Sens. 2003, 24, 1111-1117. [CrossRef]

42. Toms, J.D.; Lesperance, M.L. Piecewise regression: A tool for identifying ecological thresholds. Ecology 2003, 84, $2034-2041$. [CrossRef]

43. Yu, H.; Luedeling, E.; Xu, J. Winter and spring warming result in delayed spring phenology on the Tibetan Plateau. Proc. Natl. Acad. Sci. USA 2010, 107, 22151-22156. [CrossRef]

44. Piao, S.L.; Wang, X.H.; Ciais, P.; Zhu, B.; Wang, T.; Liu, J. Changes in satellite-derived vegetation growth trend in temperate and boreal Eurasia from 1982 to 2006. Glob. Chang. Biol. 2011, 17, 3228-3239. [CrossRef]

45. Borcard, D.; Legendre, P.; Drapeau, P. Partialling out the spatial component of ecological variation. Ecology 1992, 73, 1045-1055. [CrossRef]

46. Oksanen, J.B.F.; Kindt, R.; Legendre, P.; O’hara, R.; Simpson, G.; Solymos, P.; Stevens, M.; Wagner, H. Multivariate Analysis of Ecological Communities. Version 1. Available online: http:/ / cran.rproject.org/package=vegan (accessed on 1 May 2021).

47. Yang, Y.Z.; Wang, H.; Harrison, S.P.; Prentice, I.C.; Wright, I.J.; Peng, C.H.; Lin, G.H. Quantifying leaf-trait covariation and its controls across climates and biomes. New Phytol. 2019, 221, 155-168. [CrossRef]

48. Yamaura, Y.; Blanchet, F.G.; Higa, M. Analyzing community structure subject to incomplete sampling: Hierarchical community model vs. canonical ordinations. Ecology 2019, 100, e2759. [CrossRef]

49. Gill, A.L.; Gallinat, A.S.; Sanders-DeMott, R.; Rigden, A.J.; Gianotti, D.J.S.; Mantooth, J.A.; Templer, P.H. Changes in autumn senescence in northern hemisphere deciduous trees: A meta-analysis of autumn phenology studies. Ann. Bot. 2015, 116, 875-888. [CrossRef] [PubMed]

50. Zhang, Y.; Commane, R.; Zhou, S.; Williams, A.P.; Gentine, P. Light limitation regulates the response of autumn terrestrial carbon uptake to warming. Nat. Clim. Chang. 2020, 10, 739-743. [CrossRef]

51. Chen, H.; Zhu, Q.; Wu, N.; Wang, Y.; Peng, C.-H. Delayed spring phenology on the Tibetan Plateau may also be attributable to other factors than winter and spring warming. Proc. Natl. Acad. Sci. USA 2011, 108, E93. [CrossRef] [PubMed]

52. Sun, J.; Liu, M.; Fu, B.; Kemp, D.; Zhao, W.; Liu, G.; Han, G.; Wilkes, A.; Lu, X.; Chen, Y.; et al. Reconsidering the efficiency of grazing exclusion using fences on the Tibetan Plateau. Sci. Bull. 2020, 65, 1405-1414. [CrossRef]

53. Wu, G.-L.; Du, G.-Z.; Liu, Z.-H.; Thirgood, S. Effect of fencing and grazing on a Kobresia-dominated meadow in the QinghaiTibetan Plateau. Plant. Soil 2009, 319, 115-126. [CrossRef]

54. Li, G.Y.; Jiang, C.H.; Cheng, T.; Bai, J. Grazing alters the phenology of alpine steppe by changing the surface physical environment on the northeast Qinghai-Tibet Plateau, China. J. Environ. Manag. 2019, 248, 109257. [CrossRef]

55. Badingquiying; Smith, A.T.; Harris, R.B. Summer habitat use of plateau pikas (Ochotona curzoniae) in response to winter livestock grazing in the alpine steppe Qinghai-Tibetan Plateau. Arct. Antarct. Alp. Res. 2018, 50, e1447190. [CrossRef]

56. CaraDonna, P.J.; Iler, A.M.; Inouye, D.W. Shifts in flowering phenology reshape a subalpine plant community. Proc. Natl. Acad. Sci. USA 2018, 115, E9993. [CrossRef]

57. Visser, M.E.; Gienapp, P. Evolutionary and demographic consequences of phenological mismatches. Nat. Ecol. Evol. 2019, 3, 879-885. [CrossRef] [PubMed]

58. Teufel, B.; Sushama, L.; Arora, V.K.; Verseghy, D. Impact of dynamic vegetation phenology on the simulated pan-Arctic land surface state. Clim. Dyn. 2019, 52, 373-388. [CrossRef]

59. Jin, J.; Wang, Y.; Zhang, Z.; Magliulo, V.; Jiang, H.; Cheng, M. Phenology Plays an Important Role in the Regulation of Terrestrial Ecosystem Water-Use Efficiency in the Northern Hemisphere. Remote Sens. 2017, 9, 664. [CrossRef]

60. Liu, Y.; Wu, C. Understanding the role of phenology and summer physiology in controlling net ecosystem production: A multiscale comparison of satellite, PhenoCam and eddy covariance data. Environ. Res. Lett. 2020, 15, 104086. [CrossRef]

61. Palacio, S.; Maestro, M.; Montserrat-Marti, G. Seasonal dynamics of non-structural carbohydrates in two species of mediterranean sub-shrubs with different leaf phenology. Environ. Exp. Bot. 2007, 59, 34-42. [CrossRef]

62. Peng, J.; Wu, C.Y.; Zhang, X.Y.; Ju, W.M.; Wang, X.Y.; Lu, L.L.; Liu, Y.B. Incorporating water availability into autumn phenological model improved China's terrestrial gross primary productivity (GPP) simulation. Environ. Res. Lett. 2021, 16, 094012. [CrossRef] 